\title{
Factors Predictive of Return to Work After Stroke in Patients With Mild-Moderate Disability in India
}

\section{Citation}

Bonner, Bryant. 2015. Factors Predictive of Return to Work After Stroke in Patients With MildModerate Disability in India. Doctoral dissertation, Harvard Medical School.

\section{Permanent link}

http://nrs.harvard.edu/urn-3:HUL.InstRepos:17295878

\section{Terms of Use}

This article was downloaded from Harvard University's DASH repository, and is made available under the terms and conditions applicable to Other Posted Material, as set forth at http:// nrs.harvard.edu/urn-3:HUL.InstRepos:dash.current.terms-of-use\#LAA

\section{Share Your Story}

The Harvard community has made this article openly available.

Please share how this access benefits you. Submit a story.

\section{Accessibility}




\section{Table of Contents}

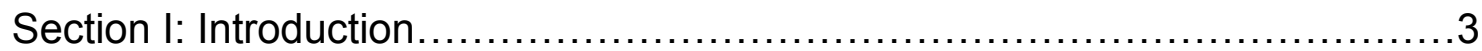

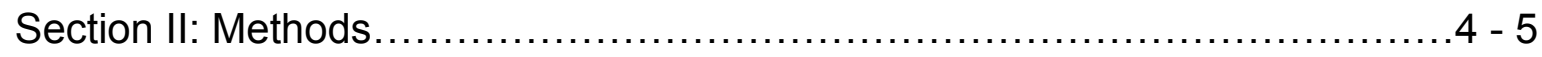

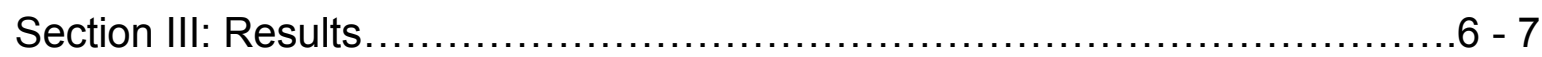

Sections IV: Discussion, Limitations, Future Directions........................ 8 - 11

Sections V: References........................................................ 15

Section VI: Tables and Figures................................................ 19

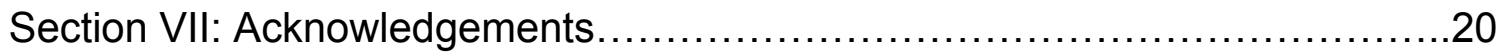




\section{Section I: Introduction}

Stroke remains one of the leading causes of morbidity and mortality across the world and its impact only continues to grow. An astonishing 20 million people every year will have a stroke, 5 million of whom will not survive and $85 \%$ of those deaths occurring in developing countries ${ }^{24}$. Of those who do survive, $20 \%$ will require institutional care after 3 months and $15-30 \%$ will be permanently disabled ${ }^{51}$.

Stroke is clinically defined by the WHO as the rapid development of clinical signs and symptoms of a focal neurological disturbance lasting more than 24 hours or leading to death with no apparent cause other than vascular origi ${ }^{52}$. Stroke can be further defined by its pathophysiology: ischemic or hemorrhagic. Hemorrhagic strokes are caused by hemorrhage in the subarachnoid or intracerebral regions and are the minority of strokes worldwide. Ischemic strokes are the most common, accounting for $50-85 \%$ of strokes worldwide and are caused by either cerebral embolism or thrombosis ${ }^{53}$. The site and extent of injury determine the signs and symptoms of a stroke but do not necessarily reveal the cause or causes. Unfortunately, reliable stroke morbidity and mortality data is difficult to obtain due to a number of reasons, including, but not limited to incomplete death certification and incorrect death classification, but one thing is certain, stroke is on the rise in India.

Exploding economic growth in India has resulted in a shift in its health burden, from infectious diseases to lifestyle disorders, of which stroke is at the forefront. A number of factors have contributed to this shift, including both modifiable and non-modifiable factors. Age, sex, and ethnicity contribute to the non-modifiable factors, while modifiable factors range from smoking, hypertension, and hypercholesterolemia. The general population is living longer and lifestyles have begun to change to resemble those more common in developed countries with less beneficial food choices and a decrease in physical activity. As a result, stroke prevalence has only continued to rise. In the city of Trivandrum, a large capital city in Southern India, stroke prevalence rates are as high as 135 per 100,000 with $12 \%$ occurring in patients $<40$ years ${ }^{45}$. In India as a whole, stroke prevalence rates are 55.6 per 100,000 and stroke accounts for 630,000 deaths/year $^{46}$. 
As stroke becomes ever more prevalent in India, it's effects can be seen beyond just the individual level. Stroke is one of the most expensive diseases in the world with costs totaling billions of dollars in direct care, lost productivity, and long-term support. It is likely that in the near future India will be faced with a significant socioeconomic burden to meet the costs of managing stroke ${ }^{24}$. While the economic burden resulting from stroke alone has not been studied in depth, India is estimated to have lost 8.7 billion (1998 international dollars) in 2005 due to coronary heart disease, stroke, and diabetes and the cost is expected to increase upwards of 54 billion (1998 international dollars) by $2015^{46}$. As the population ages and life expectancy grows, the economic impact of stroke is likely to only increase.

Stroke is not only a major health care and economic problem, but also affects patients' quality of life. Successful return to work after stroke has been shown to improve the quality of life and overall life satisfaction as well as economic circumstances ${ }^{1,2}$. Worldwide, the number of stroke patients who return to work varies significantly from $14 \%$ to $73 \%{ }^{3,4}$. A recent study conducted in South India showed that among stroke survivors, $62 \%$ were employed before the stroke, but only $20 \%$ were still working after the event, with half changing jobs after stroke ${ }^{4}$.

Despite the economic cost of lost employment, factors surrounding successful return to work after stroke have yet to be fully explored, especially in developing countries. The severity of stroke, the extent of disability, rehabilitation, and the type of employment all play important roles in the ability of patients to return to work. ${ }^{2,3}$ Yet few studies have focused on this topic worldwide and none before have done so in India ${ }^{1,2}$. Worldwide, the number of stroke patients who return to work varies widely from 11 to $85 \%$ but no data has existed for India prior to our study ${ }^{3,42}$.

It is well documented that the type of stroke, extent of disability, rehabilitation, type of job, and education level, all play important roles in the ability of patients to return to work. The greater the neurological or functional disability the less likely the individual is to return to work. Along those same lines better return to work rates are associated with 
younger age, better adjustment to disability, higher education levels, white collar professions, and early admission (within the first 12 weeks) into a rehabilitation program $11,34,19,10$. In addition, it has been shown that previously employed patients under the age of 65 years—of whom nearly $90 \%$ were independent in activities of daily living - who were unable to return to work had a decreased quality of life 4 years after stroke ${ }^{54}$.

Nevertheless, in spite of this information there remains a large gap in our knowledge of the influence of psychosocial and social factors on the return to work. Several studies have suggested that mental health and social support factors may also play an important role in the return to work. Two studies in particular demonstrated that living alone and depression at the time of follow up was associated with a decreased rate of return to work compared to age-matched stroke patients ${ }^{10,50}$, but by and large the areas remain relatively unexplored. Stroke patients often express feelings of hopelessness, helplessness, anxiety, and depression in addition to decreased social contact and growing isolation ${ }^{48,49}$. Many patients acknowledge emotional or psychological issues after a stroke, including anxiety and depression, and interestingly, many patients reporting that these conditions were even more debilitating than any physical disability ${ }^{47}$. Previous studies evaluating psychosocial factors have been limited in scope and none have taken place in India.

Moreover, the support from one's family, friends and co-workers appears to be an important, positive influence on a patient's decision to return to work after a stroke ${ }^{32}$. In fact, high levels of social support were shown to result in overall faster and an increased range of recovery of functional status following stroke ${ }^{26}$. Therefore, mental health and social support factors may also play an important role in the successful return to work, but few studies have addressed the role of the psychosocial factors in this regard.

As stroke continues to become an increased health burden in India, these issues have taken on an added importance and can no longer be ignored. In order to fill these knowledge gaps, we sought to determine what proportion of previously employed patients with mild to moderate disability return to work after stroke. We focused on 
patients without severe physical disability because we expected that these patients would be more likely to return to work. Accordingly, we conducted a cross-sectional study to examine the association between functional disability, psychosocial, and other factors in the decision to return to work after stroke. The impact of stroke in India is only expected increase the near future, so exploring these issues regarding the return to work after a stroke is especially important as physicians, hospitals, and ultimately policy makers begin to form policies to confront not only the prevention, but also the management of stroke patients. 


\section{Section II: Methods:}

Setting and Patient Population:

The study was conducted at the Sree Chitra Tirunal Institute for Medical Sciences and Technology (SCTIMST) in Trivandrum, a tertiary medical center in India specializing in neurological and cardiovascular disorders.

Study participants were recruited from the stroke clinic at SCTIMST. Adult patients ( $\geq 18$ years of age) who had an acute stroke (ischemic or hemorrhagic) at least 3 months prior (but not more than 2 years ago) and who reported working prior to the stroke event were included in the study. Work was defined as any self-reported paid employment whether it was part-time, full-time, or self-employed. Furthermore, return to work (RTW) was defined as resuming any sort of paid employment whether it is old or new employment.

Patients were excluded if they were severely disabled (modified Rankin Score $>3$ at 3 months to 2 years post stroke), were unemployed prior to their stroke, or did not speak or write in Malayalam or English.

\section{Study Design}

Participants were approached during clinic visit and study staff fluent in the local language of Malayalam distributed written questionnaires. Illiterate patients were invited to participate with the assistance of a staff member. Our structured multiple-choice questionnaire was used to examine many factors that we hypothesized as being important in an individual's decision to return to work following a stroke as well as those that have been previously shown to have an association with return to work in stroke patients. These surveys collected basic demographic information such as age, gender, marital status, income, information about employment before their stroke -type of job, complexity involved, and education level. Questions were asked about the reasons for not returning to work: e.g. lack of rehabilitation services, depression/anxiety, social 
support available (marital status, living situation, family, friends, etc), alcohol/tobacco use, termination by employer, fear/lack of confidence.

Previously validated instruments were used to assess anxiety and depression (Hospital Anxiety and Depression Scale [HADS] ${ }^{5}$ and social supports (Duke-UNC Functional Social Support Questionnaire [FSSQ] ${ }^{6}$ The HADS consists of 7 items for assessment of anxiety and 7 for depression, with each item scored from 0 (no problem) to 3 (severe problem). Scores on individual items can be summed to calculate a score for anxiety (HADS-Anxiety) and for depression (HADS-Depression). Scores $\geq 11$ points for a subscale are indicative of mood disturbance. The FSSQ consists of 8 questions with responses to each question scored on a 1 to 5 scale. "As much as I would like" receives a score of 5 and "Much less than I would like" receives a score of 1 . The scores from all eight questions are summed (maximum 40) and then divided by 8 to get an average score. The higher the average score, the greater the perceived social support. Information about stroke type (hemorrhagic versus ischemic), stroke severity, functional disability, risk factors, as well as utilization of rehabilitation services was collected. All study participants provided written informed consent and the Institutional Ethics committee approved the study.

Statistical Analysis

Patient response to the question: "Are you currently working?" was used to determine proportion of patients returning to employment. Results were summarized by reporting responses on all questionnaire items by all five Likert response categories. Several items were selected for more detailed analyses on characteristics of interest (presence of depression, psychological barriers, and social support factors). For ease of presentation, the five Likert response categories were collapsed into three categories (strongly agree and agree, neutral, strongly disagree and disagree). Chi-square tests were used to assess the association between selected respondents' characteristics and their responses. Statistical significance was defined as $\mathrm{P}<0.05$. 


\section{Section III: Results}

A total of 141 patients were included in the study. The average age of the population was $48.0+/-8.8$ years and $98 \%$ were men. Most patients were married (89\%) with only $1 \%$ being divorced or separated and $9 \%$ never being married. The average educational level was high, with $70 \%$ of patients reporting having completed at least high school or above. The majority of strokes were ischemic $(82 \%)$ with patients having NIHSS and mRS scores of $6.7 \pm 4.5$ and $3.1 \pm 4$.3, respectively, documented at stroke onset. The mean mRS score was $1.7 \pm 1.3$ at 3 months after stroke, and NIHSS and mRS scores were $1.85 \pm 2.2$ and $1.3 \pm 1.2$, respectively, at study recruitment during the clinic visit occurring $8.2 \pm 5.7$ months following stroke. The majority of strokes were attributed to large artery atherosclerosis (22\%) and small vessel occlusion (22\%). Fifty-nine percent of patients participated in some form of rehabilitation, but most did not continue for extended periods of time with only $28 \%$ participating in outpatient physiotherapy and $35 \%$ in home therapy for at least 3 months.

Forty two percent of patients met HADS criteria for depression while $56 \%$ of patients met criteria for anxiety. Average social support scores as measured by the Duke FSSQ were $32.7 \pm 7.4$ out of a total of 40 possible points.

Patients had a wide variation in the jobs with an even distribution between manual labor, office work, and business (17\% each) and a large number of patients holding other job categories such as driver (36\%). Approximately half, $74(52.5 \%)$ returned to work after stroke. Of those who returned to work, $64(86.5 \%)$ returned to their previous employer. The mean time from stroke to return to work was 3.9+4.6 months. 44 (59\%) of the participants returned to work within 3 months after the stroke onset. Among those who were unable to return to work, $63(94 \%)$ reported a desire to RTW. Among those who returned to work, fatigue (74\%) and feeling that they have not recovered $(77 \%)$ were major concerns.

Using multivariate analysis, several factors were identified that were associated with a successful RTW. These factors included: age less than 50 years (OR $2.26,95 \% \mathrm{Cl}$ 
1.04-4.89), professional as well as business jobs (OR 2.61, 95\% Cl $1.6-5.97$ ), as well as lower mRS scores at 3 months post stroke (OR 2.68, 95\% $\mathrm{Cl} 1.08-6.02)$.

Participation in rehabilitation was not associated with successful return to work. Additionally, social support $(p=0.21)$ as well as anxiety $(p=0.17)$ and depression $(p=0.61)$ defined by HADS criteria were not associated with a successful RTW. 


\section{Section IV: Discussion, Limitations, and Future Directions}

We found that approximately half $(52.5 \%)$ of previously employed stroke survivors with mild-moderate disability were able to return to work in our study in India. This proportion is consistent with the results of other studies worldwide ${ }^{7,8,9}$; however, ours was the first study looking at RTW in India among patients with mild to moderate disability. Our study revealed that professional or business employment, lower mRS scores 3 months post stroke, and younger age were associated with a successful RTW. Interestingly, lower levels of anxiety and depression and good social support did not increase the chance of successful RTW. As expected, functional disability is a major determinant in one's decision and ability to RTW. ${ }^{8-12}$. A lower level of functional disability at stroke onset and a lower level of functional disability at 3 months were significantly associated with a successful return to work in our study.

The educational level of the stroke survivors is also a factor associated with RTW and higher education levels ( $\geq$ high school equivalent) favors successful RTW. Participants with higher educational level may be able to find employment that requires fewer functional skills, flexible hours, and lends itself to easier accommodation of their return. Nevertheless, they may face difficulties with impaired cognition, speech, and fine motor skills associated with professional or business employment. Although educational level was not a major factor for successful return to work in our study, professional and business employment was a significant factor for RTW in previous studies, suggesting occupational characteristics determine successful RTW ${ }^{7}$. Several previous studies have also shown that people employed in white collar jobs are more likely to return to work $^{9,10,11}$.

Rehabilitation plays an especially important role in the return to work. More than $50 \%$ of patients who were referred for vocational rehabilitation were able to return to work and rated return to work as important for improved quality of life. ${ }^{2,44}$ Rehabilitation may ameliorate functional disability and our study confirmed that rehabilitation participation in general and home therapy in particular is associated with RTW. However, our study showed that outpatient physiotherapy and speech therapy are not associated with RTW. 
It's unclear why home therapy in particular is associated with a successful RTW and other forms of rehabilitation services are not. It may be that home therapy is likely to result in more active participation from family members in the rehabilitation process and previous studies have shown that family support is an important indicator to a successful RTW. However, despite the importance of rehabilitation for successful RTW, rehabilitation services are frequently unavailable in India. Although most stroke centers are situated in urban areas in India, $70 \%$ of the population lives in rural areas, resulting in stroke care and rehabilitation services being out of the reach of most patients in India. ${ }^{24,35}$ As a result, many stroke patients in India are likely to receive little to no rehabilitation to help them transition back to work.

Psychosocial factors may impact RTW as well, with support from one's family, friends and co-workers being an important, positive influence on a patient's decision to return to work after a stroke. ${ }^{32}$ High levels of social support have previously been shown to result in overall faster and an increased range of recovery of functional status following stroke. ${ }^{26}$ Our study did not show a significant relationship between high levels of social support and RTW. Culturally, family life plays an important role in India and both those who RTW and did not RTW experienced similarly high levels of social support $(p=0.21)$. Therefore, it was difficult to accurately probe different levels of social support and its association with RTW. The Duke-UNC FSSQ measurement tool is a reliable and validated measurement tool for perceived social support in a myriad of different patient populations and its results should be valid. Yet, social support warrants further investigation in a population where differences in social support are better appreciated.

The flexibility and attitudes of the employer and employment also seem to play an important role in one's ability to RTW. More than $85 \%$ of participants acknowledged receiving accommodations to assist in their RTW and it may have enabled them to RTW. No participants reported that they were fired from their job suggesting a willingness of employers to accept patients back after a stroke. Despite these findings, stroke survivors may not be able to perform at the same or similar level as before their stroke and this may influence their employment options. Most patients who RTW 
worked shorter hours and many remarked that they felt increased fatigue, decreased stamina, and had a lack of confidence in their skills compared with prior to the stroke.

Looking beyond the obvious functional disabilities, stroke survivors also face a number of cognitive and psychosocial barriers following their stroke that are not always explored. Post stroke depression is common among stroke survivors, reported in up to a third of stroke survivors and can adversely affect one's decision and ability to RTW. ${ }^{1,2}$ However, our study did not reveal a significant association between depression or anxiety and one's RTW. While a little surprising, recent studies have shown similar results. ${ }^{31}$ The HADS Anxiety and Depression questionnaire has been validated and performs well in assessing the symptom severity and caseness of anxiety disorders and depression in both somatic, psychiatric and primary care patients, and in the general population ${ }^{35}$, but we simply did not have a large number of patients who were depressed and anxious in either group. As a result, similar to social support, it was difficult to determine the association between these psychosocial factors and a successful RTW. Our results suggest that functional disability may be more important than anxiety and depression in one's RTW.

Our study has some limitations. We included a relatively small number of participants from one large stroke center in India. While it provides important information about factors associated with RTW, our findings may not be generalizable to the rest of India. Additionally, we could not encompass the full breadth of factors that may influence one's decision to RTW and did not consider issues like aphasia, cognitive impairment and post stroke fatigue, which may equally important in RTW. Nevertheless, our study provides insights into some of the factors that play a role in one's decision to RTW in India and lays the foundation for future work that will continue to identify unknown factors associated with, as well as barriers to a successful RTW.

As the incidence of stroke continues to grow in India, the economic burden of stroke will be further pushed to forefront of discussion and it will be important to understand the factors associated with helping patients RTW. This is especially important in 
Trivandrum, India where patients after stroke do not receive any financial support due to disability and they have little support with respect to healthcare spending on their chronic illness. Our study has begun to address these issues by documenting rates of RTW among patients with mild-moderate disability in India and by identifying several factors important to a successful RTW. Our study provides support for efforts to improve the accessibility and availability of rehabilitation services to help facilitate patient's RTW and future research focused on identifying other factors to facilitate return to work among a growing group of patients. 


\section{Section V. References}

1. Angeleri F, Angeleri VA, Foschi N, Giaquinto S, Nolfe G. The influence of depression, social activity, and family stress on functional outcome after stroke. Stroke. 1993 24(2)1478-83.

2. Vestling M, Tufvesson B , Iwarsson S. Indicators for return to work after stroke and the importance of work of subjective well being and life satisfaction. Rehabil Med 2003; 35(4):127-131.

3. Treger I, Shames J, Giaquinto S, Ring H. Return to work in stroke patients. Disability and Rehabilitation 2007; 29(3): 1397-1403.

4. Sreedharan SE, Unnikrishnan JP, Amal MG, Shibi BS, Sarma S, Sylaja PN. Employment status, social function decline and caregiver burden among stroke survivors. A South Indian study. J Neurol Sci. 2013; 15(332): 97-101.

5. Bjelland, Dahl AA, Haug TT, Neckelmann D. The validity of the hospital anxiety and depression scale. An updated literature review. J Psychosom Res 2002; 52(4): 69-77.

6. Broadhead WE, Gehlbach SH, de Gruy FV, Kaplan BH. The Duke-UNC Functional Social Support Questionnaire. Measurement of social support in family medicine patients. Med Care. 1988 ;26(4) 709-23.

7. Tanaka $\mathrm{H}$, Toyonaga $\mathrm{T}$, Hashimoto H.Functional and occupational characteristics predictive of a return to work within 18 months after stroke in Japan: implications for rehabilitation. Int Arch Occup Environ Health. 2014 87(5): 445-53.

8. Peters GO, Buni SG, Oyeyemi AY, Hamzat TK. Determinants of return to work among Nigerian stroke survivors.. Disabil Rehabil. 2013;35(22): 455-9.

9. Saeki S, Ogata H, Okubo T, Takahashi K, Hoshuyama T. Factors influencing return to work after stroke in Japan. Stroke.1993;24(3): 1182-5.

10.Wozniak MA, Kittner SJ, Price TR, Hebel JR, Sloan MA, Gardner JF. Stroke location is not associated with return to work after first ischemic stroke. Stroke 1999;30(23): 2568-73.

11. Howard G, Till JS, Toole JF, Matthews C, Truscott BL: Factors influencing return to work following cerebral infarction. JAMA 1985;253(27): 226-232.

12. Wang Y C, Kapellusch J, Garg A. Important factors influencing the return to work after stroke. Work. 2013;27(2): 876-82 
13. Busch, M.A., Coshll, C., \& Heuschmann, P.U. Sociodemographic differences in return to work after stroke: the South London Stroke Register , Eurol. Neurosurg. Psychiatry. 2009;80(20): 888-893

14. Andersen G,Christensen D,Kirkevold M,Johnsen SP. Post stroke fatigue and return to work: a 2 year followup. Acta Neurol Scand 2012;125(34):248-253.

15. Brey JK, Wolf TJ.Socioeconomic disparities in work performance following mild stroke. Disabil Rehabil 2014; epub ahead of print.

16. Andersen G,Christensen D,Kirkevold M,Johnsen SP. Post stroke fatigue and return to work: a 2 year followup. Acta Neurol Scand 2012;125(3):248-253.

17. Abhishek Srivastava, Arun B. Taly, Anupam Gupta, and Thyloth Murali; Post-stroke depression: Prevalence and relationship with disability in chronic stroke survivours; Ann Indian Acad Neurol. 2010;13(2): 123-127

18. Alaszewski, A., Alaszewski, H., Potter, J., \& Penhale, B. Working after a stroke: Survivors' experiences and perceptions of barriers to and facilitators for the return to paid employment. Disability and rehabilitation 2007;29(24): 1858-1869.

19. Bergmann $H$, Kurthman $M$, von Ungern-Sternberg A, Weimann VG. Medical educational and functional determinants of employment after stroke. J Neural Transm 1991 (Suppl.);33(2):157-61

20. Black-Schaffer RM, Osberg JS. Return to work after stroke: development of a predictive model. Arch Phys Med Rehabil. 1990;71(5):285-90.

21. Busch, M.A., Coshll, C., \& Heuschmann, P.U. Sociodemographic differences in return to work after stroke: the South London Stroke Register , Eurol. Neurosurg. Psychiatry 2009; 80(9): 888-893

22. Carol Coole, Kathryn Radford, Mary Grant, Jane Terry. Returning to Work After Stroke: Perspectives of Employer Stakeholders, a Qualitative Study. Occup Rehabil 2007 87(9):212-17

23. Corr S, Wilmer S. Returning to Work after a Stroke: an Important but Neglected Area .British Journal of Occupational Therapy, 2003;66(5):186-192

24. Dalal $P, B$ Battacharjee $M$, Vairale J, Bhat $P$. UN millennium development goals: can we halt thedisease and stroke in India. Heart 2008; 94(2):16-26.

25. George Howard, MSPH; J. Stanwood Till, ; James F. Toole; Claire Matthews; B. Lionel Truscott . Factors Influencing Return to Work Following Cerebral InfarctionJAMA. 1985; 253(2):226-232. 
26. Glass TA, Matchar DB, Belyea M, Feussner JR: Impact of social support on outcome in first stroke. Stroke 1993; 24(2):64-70.

27. Hirotaka Tanaka,Toshihiro Toyonaga, Hideki Hashimot. Functional and occupational characteristics predictive of a returnto work within 18 months after stroke in Japan: implications for rehabilitation. Int Arch Occup Environ Health. 2013; 56(3):346-55

28. Howard G, Till JS, Toole JF, Matthews C, Truscott BL: Factors influencing return to work following cerebral infarction. JAMA 1985;253(31):226-232.

29. Japp, J. Brain Injury and Returning to Employment: A Guide for Practitioners. London \& Philadelphia: Jessica Kingsley Publishers 2005

30. Javier Carod-Artal; José Antonio Egido; José Luis González; E. Varela de Seijas. Quality of Life Among Stroke Survivors Evaluated 1 Year After Stroke Experience of a Stroke Unit. Stroke. 2000; 31(5):2995-3000

31. Maree L. Hackett,' Nick Glozier, Stephen Jan, Richard Lindley. Returning to Paid Employment after Stroke: The Psychosocial Outcomes In StrokE (POISE) Cohort Study. PLoS One. 2012; 7(7):417-25

32. Medin J, Barajas J, Ekberg K. Stroke patients' experiences of return to work. Disabil Rehabil. 2006;28(17):1051-60.

33. Meyer B C, Hemmn T M, Jackson C M, Lyden P D, Modified National Institutes of Health Stroke Scale for Use in Stroke Clinic Trials; Stroke 2002; 33 (2):1261-1266.

34. Neau JP, Ingrand P, Mouille-Brachet C, Rosier MP, Couderq C, Alvarez A, Gil R. Functional recovery and social outcome after cerebral infarction in young adults. Cerebrovasc Dis 1998;8(4):296 - 302.

35. Pandian JD, Srikanth V, Read SJ, Thrift AG. Poverty and stroke in India: a time to act. Stroke. 2007;38(11):3063-9.

36. Peters GO, Buni SG, Oyeyemi AY, Hamzat TK. Determinants of return to work among Nigerian stroke survivors. Disabil Rehabil. 2013;35(13):455-9.

37. Röding J, Lindström B, Malm J, Ohman A.Frustrated and invisible--younger stroke patients' experiences of the rehabilitation process. Disabil Rehabil. 2003;25(15):867-68

38. Saeki S, Ogata H, Okubo T, Takahashi K, Hoshuyama T.Factors influencing return to work after stroke in Japan. Stroke. 1993;24(8):1182-5

39. Shames J, Treger I, Ring H, Giaquinto S. Return to work following traumatic brain injury: trends and challenges. Disabil Rehabil. 2007; 29(17):1387-95. 
40. Sven Trygged, Kozma Ahacic'Ingemar Kåreholt ; Income and education as predictors of return to working life among younger stroke patients ; BMC Public Health 2011, 11(2):742

41. Wang Y C, Kapellusch J, Garg A. Important factors influencing the return to work after stroke.. Work. 2013 [Epub ahead of print)

42. Wolfenden B, Grace M. Returning to work after stroke: a review. International J Rehabil Res. 2009 Jun;32(7):93-7.

43.Gabriele W, Renate S.. Work loss following stroke. Disability and Rehabilitation 2009;31(15):1487-1493.

44. Wozniak M.A, Kittner S.J.. Return to work after ischemic stroke: A methodological review. Neuroepidemiology. 2002;21(4): 159-166

45. Sridharan SE, Unnikrishnan JP, Sukumaran S, Sylaja PN, Nayak SD, Sarma PS, Radhakrishnan K. Incidence, types, risk factors, and outcome of stroke in a developing country: the Trivandrum Stroke Registry. Stroke. 2009;40(4):1212-8.

46. UK National Audit Office (NAO), "Reducing Brain Damage: Faster access to better stroke care". 2005

47. Barker, Graham. Getting Back to Work after Stroke. Rep. Ed. Katherine Wiggins. London, UK.Stroke Association, 2006.

48. Chang AM, Mackenzie AE. State self-esteem following stroke. Stroke.1998; 29(2): 2325-2328

49. Raju R, Sarma PS, and Pandian JD. Pyschosocial problems, Quality of Life, and Functional Independence Among Indian Stroke Survivors. Stroke 2010, 41(12): 29322937

50. Niemi ML, Laaksonen R, Kotila M, Waltimo O. Quality of life 4 years after stroke. Stroke. 1988;19(9):1101-7.

51. Adams $\mathrm{R}$ et al. Update of the AHA/ASA recommendations for the prevention of stroke in patients with stroke and transient ischaemic attacks. Stroke 2008; 39(2): 164752

52. Gupta R, Joshi P, Mohan V, Reddy S, Yusuf S. Epidemiology and causation of coronary heart disease and stroke in India. Heart 2008; 94(11): 16-26

53. Feigin V, Lawes C, Bennet D, Barker_Cello S, Parag V. Worldwide stroke incidence and early case fatality in 56 population based studies: a systematic review. Lancet Neurology 2009; 8 (4): 355- 369 


\section{Section VI: Tables and Figures}

Table 1: Patient Demographics

Total

$\begin{array}{llll} & \text { Return } & \text { Did not } & \text { P-value Comparison } \\ \text { Population } & \text { to work } & \text { RTW } & \text { of RTW vs. Did } \\ (n=141) & (n=74) & (n=67) & \text { not RTW }\end{array}$

DEMOGRAPHICS

\begin{tabular}{|c|c|c|c|c|}
\hline Age \pm SD & $48.0+8.8$ & $46.7+9.1$ & $49.5+8.3$ & 0.06 \\
\hline Sex (\% Male) & $98 \%$ & $97 \%$ & $99 \%$ & 0.6 \\
\hline \multicolumn{5}{|l|}{ Marital Status } \\
\hline Married & $89 \%$ & $86 \%$ & $94 \%$ & 0.13 \\
\hline Never Married & 9\% & $12 \%$ & $6 \%$ & 0.2 \\
\hline Divorced/Separated & $1 \%$ & $1 \%$ & $0 \%$ & 0.34 \\
\hline \multicolumn{5}{|l|}{ Highest Educational Level } \\
\hline Secondary School or below & $25 \%$ & $22 \%$ & $30 \%$ & 0.19 \\
\hline High School or above & $70 \%$ & $72 \%$ & $69 \%$ & 0.19 \\
\hline \multicolumn{5}{|l|}{ STROKE DETAILS } \\
\hline Months since Stroke & $8.2+5.7$ & $8.8+5.8$ & $7.6+5.6$ & 0.2 \\
\hline $\begin{array}{l}\text { Type of stroke } \\
\text { (\% ischemic stroke) }\end{array}$ & $82 \%$ & $80 \%$ & $87 \%$ & 0.5 \\
\hline \multicolumn{5}{|l|}{ NIHSS Score \pm SD } \\
\hline Onset & $6.7+4.5$ & $5.9+4.4$ & $7.6+4.4$ & 0.03 \\
\hline Today & $1.85+2.2$ & $1.1+1.9$ & $2.8+2.3$ & 0.00004 \\
\hline \multicolumn{5}{|l|}{$\mathrm{mRS} \pm \mathrm{SD}$} \\
\hline Onset & $3.1+1.3$ & $2.88+1.3$ & $3.4+1.1$ & 0.02 \\
\hline 3 Months & $1.7+1.3$ & $1.2+1.1$ & $2.2+1.3$ & 4.00E-06 \\
\hline Today & $1.3+1.2$ & $0.9+1.1$ & $1.8+1.1$ & 1.00E-06 \\
\hline \multicolumn{5}{|l|}{ Stroke Etiology } \\
\hline Atherosclerosis & $22 \%$ & $19 \%$ & $25 \%$ & 0.36 \\
\hline Cardioembolism & $8 \%$ & $9 \%$ & $7 \%$ & 0.67 \\
\hline Small Artery Occlusion & $22 \%$ & $22 \%$ & $22 \%$ & 0.91 \\
\hline Other Etiology & $19 \%$ & $20 \%$ & $18 \%$ & 0.72 \\
\hline Undetermined & $15 \%$ & $16 \%$ & $15 \%$ & 0.83 \\
\hline $\begin{array}{l}\text { REHAB PARTICIPATION } \\
\text { OP Physiotherapy }\end{array}$ & $59 \%$ & $49 \%$ & $71 \%$ & 0.005 \\
\hline $\begin{array}{l}\text { Participation } 3-6 \text { months } \\
\text { Home therapy }\end{array}$ & $28 \%$ & $17 \%$ & $41 \%$ & 0.09 \\
\hline
\end{tabular}




\begin{tabular}{|c|c|c|c|c|}
\hline Participation 3-6 months & $35 \%$ & $28 \%$ & $39 \%$ & 0.42 \\
\hline \multicolumn{5}{|l|}{ EMPLOYMENT DETAILS } \\
\hline \multicolumn{5}{|c|}{ Type of work before stroke } \\
\hline Manual Labor & $17 \%$ & $15.00 \%$ & $31 \%$ & 0.02 \\
\hline Office work & $17 \%$ & $20.00 \%$ & $13 \%$ & 0.28 \\
\hline Business & $17 \%$ & $23.00 \%$ & $9 \%$ & 0.02 \\
\hline Executive work & $9 \%$ & $11.00 \%$ & $4 \%$ & 0.16 \\
\hline Other (i.e Driver, coolie) & $36 \%$ & $31.00 \%$ & $42 \%$ & 0.19 \\
\hline \multicolumn{5}{|c|}{ PSYCHOSOCIAL INFROMATION } \\
\hline \multicolumn{5}{|c|}{ HADS Depression score } \\
\hline Normal (0-7) & $57 \%$ & $59 \%$ & $55 \%$ & 0.61 \\
\hline Depression $(\geq 8)$ & $42 \%$ & $41 \%$ & $45 \%$ & 0.61 \\
\hline \multicolumn{5}{|l|}{ HADS Anxiety Score } \\
\hline Normal (0-7) & $43 \%$ & $49 \%$ & $37 \%$ & 0.17 \\
\hline Anxiety $(\geq 8)$ & $56 \%$ & $51 \%$ & $63 \%$ & 0.17 \\
\hline \multicolumn{5}{|l|}{ Duke - UNC FSSQ } \\
\hline Score \pm SD & $32.7+7.4$ & $33.4+7$ & $31.9+7.7$ & \\
\hline
\end{tabular}


Table 2. Factors Associated with a successful RTW

\begin{tabular}{lll}
\hline & & \\
Factor & Adjusted OR $(95 \% \mathrm{Cl})$ & P value \\
\hline & & \\
Age $<50$ years & $2.264(1.046-4.898)$ & 0.045 \\
Male sex & $0.974(0.63-2.57)$ & 0.987 \\
Education: >=High School & $1.196(0.69-3.82)$ & 0.264 \\
Professional/business employment & $2.608(1.16-5.97)$ & 0.025 \\
Rehab participation & $0.43(0.13-1.25)$ & 0.169 \\
Home therapy & $1.126(0.40-3.20)$ & 0.828 \\
mRS at 3 months (score 0-1) & $2.685(1.08-6.02)$ & 0.031 \\
Low HADS depression score & & 0.511 \\
(Score $<6)$ & $1.327(0.76-2.88)$ & \\
Low HADS anxiety score & & 0.665 \\
$\quad$ (Score $<9)$ & $0.835(0.54-2.13)$ &
\end{tabular}


Table 3. Concerns of individuals who returned to work

\begin{tabular}{|c|c|c|}
\hline Concerns & Agree (\%) & Disagree (\%) \\
\hline Fear of having another stroke & 28.4 & 71.6 \\
\hline $\begin{array}{l}\text { Worried about the treatment of employer or } \\
\text { coworkers }\end{array}$ & 25.8 & 74.2 \\
\hline Lack of Confidence & 41.8 & 58.2 \\
\hline Feel that not fully recovered from stroke & 77.3 & 22.7 \\
\hline Not able to get a job & 32.8 & 67.2 \\
\hline Feel fatigued or decreased stamina & 74.6 & 25.4 \\
\hline
\end{tabular}




\section{Section VII: Acknowledgements}

Thank you to everyone for all his or her hard work and dedication to the completion of this project! In particular, I would like to thank the following people for their contributions:

- Dr. Sylaja PN - My on site mentor, she was instrumental to helping me to organize and complete this project. We worked together to organize the logistics of the project from everything like the best measurement tools for factors important to one's RTW to patient recruitment. She was also invaluable for her input and editing of the completed paper and completion of the IRB at Sree Chitra Tirunal Institute.

- Dr. Kasia Lipska - My HMS mentor she was amazing help for getting everything set up to her guidance along the way. She provided me with a contact in India and along with Dr. Sylaja helped me to plan out my project. She also helped with her discussion as to the correct organization and execution of the project and was invaluable for her input and editing of the completed paper.

- Ratheesh Pillai - Social Worker at Sree Chitra who was instrumental to the project completion for his help with patient recruitment and interviews with stroke patients.

- Dr. P Sankara Sarma - Professor in Biostatistics at Sree Chitra who helped with all of our data organization and analysis.

- Support staff at Sree Chitra Tirunal Stroke Center - Too many people to individually thank for their input and advice on the project as well their camaraderie and friendship during my time in India. 